\title{
AMBIGUOUS LOSS: A PHENOMENOLOGICAL EXPLORATION OF WOMEN SEEKING SUPPORT FOLLOWING MISCARRIAGE
}

\author{
By \\ KATHLEEN MCGEE \\ Bachelor of Science in Human Development and Family \\ Science \\ Oklahoma State University \\ Stillwater, Oklahoma \\ 2011
}

Submitted to the Faculty of the

Graduate College of the

Oklahoma State University

in partial fulfillment of

the requirements for the Degree of

MASTER OF SCIENCE

May, 2014 
AMBIGIOUS LOSS: A PHENOMENOLOGICAL

EXPLORATION OF WOMEN SEEKING SUPPORT

FOLLOWING MISCARRIAGE

Thesis Approved:

Dr. Kami Gallus

Dr. Amanda Harrist

Dr. Karina Shreffler 
Name: KATHLEEN MCGEE

Date of Degree: MAY, 2014

Title of Study: AMBIGUOUS LOSS: A PHENOMENOLOGICAL EXPLORATION OF WOMEN SEEKING SUPPORT FOLLOWING MISCARRIAGE

\author{
Major Field: HUMAN DEVELOPMENT AND FAMILY SCIENCE
}

Abstract:

Miscarriage is a fairly common experience that is overlooked by today's society. Miscarriage as simply a female medical issue does not embody the full emotional toll of the experience. Research is lacking on miscarriage and the couple relationship. Even further, a framework for understanding miscarriage is nonexistent. This study aims to explore the phenomenon of miscarriage as well as provide a framework for understanding miscarriage. The current study will look at miscarriage through the lenses of ambiguous loss theory and trauma theory.

The sample consisted of 10 females, five who interviewed as individuals and 5 who interviewed with their partners as a couple. Semi-structured, open-ended interviews were conducted with each individual participant, and the five couples were interviewed as a couple as well. From the data, six themes and four subthemes emerged for the female experience:

Emotional toll, Stolen dreams, No one understands, He loves me in a different way, Why? I don't understand, and In the end, I have my faith. Five themes emerged for the male experience: Shaking my faith, It's not about me, It's about her, It's so out of your control, Relief through faith, relief through knowing we are not alone. One theme emerged from interviewing couples: Strong relationships become stronger. Future research, limitations, and clinical implications are discussed. 


\section{TABLE OF CONTENTS}

Chapter




\section{LIST OF TABLES}

Table

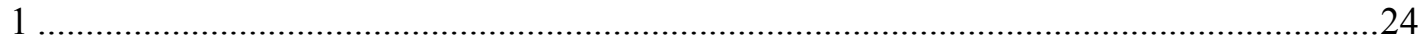




\section{CHAPTER I}

\section{INTRODUCTION}

For those who use qualitative research, it is important to understand the connection between personal experience and the topic studied (Creswell, 1998). My interest in miscarriage began when I first heard that my mother had experienced one before I was born. I found it interesting that she or my father had never spoken about their loss openly with our family. Losing a baby was a difficult thing for both of my parents, but the experience was particularly painful for my mother. It was at that time of learning about their loss that I began my journey becoming a marriage and family therapist. Throughout my work as graduate student, particularly as an intern at the Center For Family Services, I have always wondered why some experiences are spoken about more openly while others are kept quiet. I came to realize that every person has a right to their pain and a right to tell their story. Professionally and personally, I want to be someone who will listen before making a judgment on the validity of someone's story. I believe that miscarriage is one story, a painful experience that is often silenced by friends, family, professionals, and researchers. I was very curious as to why that is and how that can be changed. That was the beginning of my interest in miscarriage and the couple relationship.

Miscarriage is typically considered a female medical issue, but I believe there is more to be told. My intention for researching this topic through interviewing those who have experienced miscarriage was first to tell more of the story. Additionally, I believe that knowledge 
is power, and as we understand the experience of miscarriage more fully then we can be more sensitive to those struggling with losing a baby. Also, I hope to provide a lens through which to examine miscarriage. Ambiguous loss theory and trauma theory are both empirically supported, and if miscarriage were to be considered a traumatic ambiguous loss, then I believe those silently grieving may be better understood. In the next chapter, I present the research on miscarriage as well as research on ambiguous loss theory and trauma theory. In the third chapter, I outline the methodology. In the fourth chapter, I present the results of the study. Finally, in the fifth chapter, I discuss the findings, limitations of the current study and research implications, and clinical implications. 


\section{CHAPTER II}

\section{REVIEW OF LITERATURE}

Roughly $15 \%$ of all clinically recognized pregnancies in the United States result in miscarriage (Swanson, Chen, Graham, Wojnar, \& Petras, 2009). However, it has been estimated that when accounting for pregnancies not clinically recognized, the rate of miscarriage increases to one in five, or $20 \%$ of all pregnancies (Abboud \& Liamputtong, 2003). While miscarriage is typically considered a female medical issue, the physical as well as psychological loss associated with miscarriage can be distressing for both partners as well as the couple relationship (Brier, 2008).

The experience of miscarriage is often silenced or overlooked by professionals, families, and friends, and as a result, many individuals and couples dealing with the loss struggle with their grief (Brier, 2008). While limited studies have explored the impact of miscarriage on the couple relationship in various cultures or solely from a female perspective, research is still needed that explores both the male and female partner perspectives among couples in the United States. There is a great deal of variability when it comes to women's responses to miscarriage. (Shreffler, Greil, \& McQuillan, 2011). The context of the pregnancy as well as fertility history affects women's responses to miscarriage. For example, women who are not attached to the pregnancy may experience less distress (Shreffler, Greil, \& McQuillan, 2011). Moreover, current research has 
focused on women who view miscarriage as a distressing event. It is important to note that miscarriage is not universally distressing, but for those women for whom it is distressing, research suggests that it has significant biopsychosocial consequences. Current research could benefit from examining the experience of miscarriage for couples from a systemic perspective. A systemic perspective would include how each partner influences one another. Since research has primarily studied miscarriage from a female perspective, including the male perspective to examine the couples' experience may expand our knowledge of the phenomenon of miscarriage.

By taking a systemic perspective on miscarriage, researchers and clinicians may better understand the far reaching psychological and relational implications of this unique, yet common life experience. Even further by understanding miscarriage as an ambiguous loss and a trauma, the phenomenon may be better explained. Existing literature has theoretically defined miscarriage as an ambiguous loss, but no previous studies have specifically quantitatively or qualitatively explored miscarriage through the lens of ambiguous loss and trauma.

Therefore, the current study aims to examine miscarriage through the theoretical lenses of ambiguous loss and trauma, in order to describe both male's and females's experiences and reactions to miscarriage and how partners' reactions mutually influence each another and overall couple functioning.

\section{Miscarriage}

According to the U.S. National Library of Medicine (2012), miscarriage can be defined as the spontaneous loss of a fetus before the $20^{\text {th }}$ week of pregnancy. While maternal age, health, and nutrition are among the primary risk factors for miscarriage (Sperry \& Sperry, 2004), there are a wide variety of potential causes including drug and alcohol abuse, exposure to environmental toxins, infection, obesity, smoking, physical problems with the mother's reproductive organs, problems with the body's immune response, or chromosome problems that 
inhibit the development of the fetus unrelated to the mother's or father's genes (U.S. National Library of Medicine, 2012). Although determining a cause is sometimes possible, miscarriage often lacks a clear medical explanation (Shreffler, Greil, \& McQuillan, 2011). Knowing the physical toll a miscarriage can have on a woman, researchers have begun to acknowledge the need to understand the full impact of miscarriage, including the psychological impact.

\section{Women's Experience}

Researchers have found that miscarriage has an effect on women's psychological wellbeing. Adolfsson, Larsson, Wijma, and Bertero (2004) used qualitative interviews to identify and describe Swedish women's miscarriage experiences. Gerber-Epstein, Leichtentritt, and Bentamini (2009) also used qualitative methods to better understand women's miscarriage experiences in Israel. For Adolfsson et al. (2004) the main themes found were guilt and emptiness. Both studies found that women often feel loss not only for the life of the child, but also for the loss of their new role as a mother (Adolfsson et al., 2004; Gerber-Epstein et al., 2009). Gerber-Epstein et al. (2009) found that women reported feeling like something crashed after hearing about the pregnancy loss, as if something was broken. Broen, Moum, Bodtker, and Ekeberg (2004) found that women who miscarry experience shock, which may lead to intrusive symptoms (e.g., flashbacks, bad dreams, intense feelings related to the event). Schwerdtfeger and Shreffler (2009) found that women who have experienced miscarriage report lower life satisfaction and more depressive symptoms than women with no fertility difficulties. However, Prettyman, Cordle, and Cook (1993), as cited in Lee and Slade (1996), found that their sample of women reported more anxiety symptoms than depressive symptoms following miscarriage.

Many researchers have examined intrapersonal effects of miscarriage on women. While women grieve over miscarriage in different ways (Adolfsson et al., 2004), a common emotion reported by women experiencing miscarriage is guilt. A frequent finding is that guilt is associated 
with women's self blame for the loss, which commonly perpetuates depressive symptoms among women following miscarriage (Abboud \& Liamputtong, 2003; Adolfsson et al., 2004; Conway \& Russell, 2000; Gerber-Epstein et al. 2009). Another intrapersonal effect for women is feeling a loss of control when they miscarry, which can be a frightening experience (Adolfsson et al., 2004; Wojnar et al., 2011). Some researchers have found that many women who experience miscarriage feel like a failure as a woman, given that motherhood was a role and goal for these women (Abboud \& Liamputtong, 2003; Gerber-Epstein et al., 2009). Following the experience, seeing other women who are pregnant is often difficult for women who have experienced miscarriage as it highlights complicated feelings of failure, guilt, sadness, and even jealousy (Beutel et al., 1996; Serrano \& Lima, 2006). These intrapersonal effects and emotions, such as guilt, loss of control, feelings of failure and jealousy, may confound the healing process for women who have experienced miscarriage.

Wojnar et al. (2011) found that women who miscarry often fluctuate between hopefulness and hopelessness. This fluctuation may lead women to search for meaning after miscarriage in an attempt to resolve feelings of guilt (Simmons, Singh, Maconochie, Doyle, \& Green, 2006; Wojnar et al., 2011). Unfortunately, many women are left without explanations or reasons for the miscarriage, which disables their ability to make sense of the loss and grieve (Adolfsson et al., 2004; Simmons et al., 2006).

Another important aspect of researching miscarriage is the interpersonal effects. An important finding from two qualitative studies with women who had experienced miscarriage was the need for acknowledgement of the loss from family as well as professionals in order to combat the distress associated with the loss (Rowlands \& Lee, 2010; Simmons et al., 2006). According to McGreal, Evans, and Burrows (1997), women use social supports as a coping device more frequently than men. Women are typically more closely linked with their families of origin and friends, which allows them to turn to these networks in times of need. Women reported receiving 
the most support after miscarriage from their own mothers (Gerber-Epstein et al., 2009). While this would be an effective way to combat distress, unfortunately, not every woman has the opportunity to turn to her mother for support.

Turning to a partner for support has been found to mediate distress for women who have experienced miscarriage (Swanson et al., 2009) While turning to their partner for support may be beneficial, it may be a difficult task for some women. Beutel et al. (1996) found that women reported their male partners avoiding talking about the loss as time went on, which could also contribute to feelings of isolation for women experiencing miscarriage. Research also suggests that egocentric thinking about the miscarriage may lead a woman to forget that she has a partner who may be sharing in her experience (Gerber-Epstein et al., 2009). Since both partners may be divergently coping with the loss, asking for and/or receiving support from a partner may not be easy.

\section{Men's Experience}

Although research has primarily focused on women's experiences and responses to miscarriage, some researchers have included male participants in their studies to try to gain a better idea of gender differences and how men respond to miscarriage. Miscarriage is often viewed as the woman's loss, and men are rarely considered to have experienced the same amount of distress (Rinehart \& Kiselica, 2010). Men are often overlooked, which leaves a key piece of the miscarriage experience largely unexplored. As far as intrapersonal effects, Rinehart and Kiselica (2010) found that men may experience the same sadness as women, but men typically do not grieve as openly as women. Men have been found to experience the same grief, anxiety, and depressive symptoms after a miscarriage, but these feelings or symptoms may not be as long term (Johnson \& Baker, 2004; McGreal et al., 1997; Rinehart and Kiselica, 2010; Serrano \& Lima, 
2006). According to McGreal et al. (1997), men typically process grief faster than women following a miscarriage.

Men, similar to women, develop hopes and expectations for what it will be like to be a father to their new baby (Rinehart \& Kiselica, 2010). Researchers have also found interpersonal effects for men who experience miscarriage. Rinehart and Kiselica (2010) found that men may feel pressure to be strong and supportive for their partners, which does not give them much opportunity to deal with their own loss (Beutel et al., 1996; Klier, Geller, \& Ritsher, 2002; Rinehart \& Kiselica, 2010; Serrano \& Lima, 2006). Conway and Russell (2000) found that the male partner's reactions to the miscarriage are greatly affected by the female's reactions. In terms of interpersonal aspects, men are less likely than women to utilize social support when dealing with miscarriage (McGreal et al., 1997). Without outside support, some men attempt to deal with their emotions through externalizing behaviors such as aggression, alcohol use, or substance use (Johnson \& Baker, 2004; Rinehart \& Kiselica, 2010). These externalizing behaviors may make the recovery process difficult for individuals and couples.

\section{Couple Functioning}

Systems theory formalizes the intrapersonal and interpersonal experience and how individual functioning impacts the couple relationship and vice versa. A system is the compilation of interrelated parts and the relationships that already existed among the parts (Montgomery \& Fewer, 1988). Therefore, when researching the couple relationship, it is crucial to consider both the individuals, how the individuals influence one another, and the relationship as a whole.

Although research suggests that men and women tend to have different reactions to miscarriage, little is known about how miscarriage and individual gender differences affect couple functioning. Swanson, Karmali, Powell, and Pulvermakher (2003) found that one year after miscarriage, women report their couple relationship as more distant than it was before the 
miscarriage. Shreffler, Wonch Hill, and Cacciatore (2012) utilized survey data to explore the reasons why women who have experienced miscarriage or stillbirth are more likely to divorce than other women. This study found that women who experienced miscarriage or stillbirth were more likely to divorce than women who had not experienced those types of losses and that fertility context and background characteristics served as protective or risk factors. In particular, gestation age, experiencing the loss of a planned pregnancy, and experiencing multiple losses was linked to higher odds of divorce.

Abboud and Liamputtong (2003) interviewed six couples in Melbourne who had experienced miscarriage, in an effort to examine individual experiences and perceptions of partners' experiences. Abboud and Liamputtong (2003) examined individual experiences and perceptions of partners' experiences. Both women and men questioned why the miscarriage occurred, which is consistent with previous literature on miscarriage. In this study, women thought that their partners had a less intense reaction to the miscarriage. Men perceived their partners as having moved on sooner than the women reported moving on. The study found that communication between men and women about the miscarriage varied in level and intensity. Some women perceived their couple communication as acceptable and some found that couple communication was insufficient. Research is still needed for couples experiencing miscarriage in the U.S.

Conway and Russell (2000) utilized the Perinatal Grief Scale in order to examine male and female reactions to miscarriage. The Perinatal Grief Scale is divided into three subscales: active grief, difficulty coping, and despair. The study found that couples still experience feelings of loss and sadness up to four months after miscarriage. The study also found that women require more emotional support than men that communicates their partner shares in the loss. Conway and Russell (2000) found that many couples do not perceive professional support as beneficial. This 
finding could be due to a lack of a framework in which professionals can best understand the experience of miscarriage.

\section{Ambiguous Loss}

Conceptualizing miscarriage as an ambiguous loss may be helpful for those who have experienced miscarriage as well as for professionals working with individuals and couples who have experienced miscarriage. Betz and Thorngren (2006) define ambiguous loss as a loss that is not concrete or identifiable as traditional losses such as death. Boss (2009) defines ambiguous loss as a unique, unclear, traumatic, externally caused type of loss that has relational implications. Ambiguous loss is typically one of two types: (a) physical absence with psychological presence (i.e., divorce in which one parent moves away or when a loved one is missing), or (b) physical presence with psychological absence (i.e., having a loved one with Alzheimer's disease or an addiction)(Boss, 2010). Ambiguous loss differs from ordinary loss because the normal grief process is halted due to the uncertainty inherent in it (Boss, 2010). The difficulty with ambiguous loss is the ambiguity may heighten anxiety and make closure often impossible (Boss, 1999; Boss, 2010). Ambiguity is a difficult experience for most individuals because it inhibits normal cognitive coping (Betz \& Thorngren, 2006; Boss, 2007). Typical rituals for loss as well as stages of grief do not apply to ambiguous loss. Also, it is difficult to cognitively understand what or why the loss happened in most cases of ambiguous loss.

The experience of ambiguous loss has been associated with symptoms of posttraumatic stress disorder (PTSD)(American Psychological Association, 2000) for men and women (Boss, 2010). Boss (1999) highlights symptoms of PTSD such as anxiety, depression, and somatic illness, which are common following ambiguous losses. For those who experience ambiguous loss, the traumatizing situation remains in the present because coping is inhibited by unanswered questions such as why the event happened. Boss (2010) has found that ambiguous loss also 
resembles complicated grief; however, it is not diagnostically recognized, as is PTSD or bereavement. Boss (1999) has found that after an ambiguous loss, symptoms typically first affect the individual and then spread to relationships.

Ambiguous loss can be conceptualized as a relational phenomenon because of the implications it has within relationships (Boss, 2007). Ambiguous loss can also complicate relationship roles because individuals may repeat previous patterns of interaction that no longer fit the current situation (Betz \& Thorngren, 2006; Lang et al., 2011). Individuals may also become stuck in a helpless role because of the unresolved grief, and ambiguous loss, if not dealt with, often creates added stress for individuals as well as the relationship (Betz \& Thorngren, 2006). Boss (1999) has also found that often family members withdraw from one another and become preoccupied with the ambiguity of the loss.

Miscarriage fits the criteria of ambiguous loss because of the physical absence, but psychological presence, of a child. Lang et al. (2011) explored the ambiguity of the loss by studying couples who had experienced miscarriage. Lang et al. found multiple sources of ambiguity for these couples, such as uncertainty about the viability of the pregnancy, confusion about the actual process of losing the pregnancy, uncertainty around a ritual for the loss, and hesitation in telling others about the miscarriage. These sources of ambiguity were found to create stress for couples who experienced miscarriage (Lang et al., 2011).

Boss (2007) highlighted that ambiguous loss influences stress physically, cognitively, behaviorally, and emotionally. However, ambiguous loss is not impossible to journey through (Boss, 2007; Boss, 2010). Boss (1999) utilized the family stress perspective when working with those dealing with ambiguous loss. Boss uses three assumptions: (a) that individuals and families need information and education about the unique experience of ambiguous loss, (b) that there is a need for skills to manage the stress, and (c) that information, whether good or bad, about the 
specific loss shouldn't be withheld. Recovery from ambiguous loss involves working through ambivalence, which is conflicting thoughts and feelings or mixed emotions (Boss, 1999). Later, Boss further developed her guidelines for living with ambiguous loss (2006). Boss (2006) cited the following as ways to cope with ambiguous loss: finding meaning, tempering mastery, reconstructing identity, normalizing ambivalence, revising attachment, and discovering hope. Another important part of recovery includes making sense out of the ambiguity and maintaining optimism. Because ambiguous loss is not a typical loss, it can be difficult for individuals and families to overcome. Understanding miscarriage as an ambiguous loss may help those who are struggling with their grief. Miscarriage as a legitimate ambiguous loss could also help professionals who work with couples experiencing miscarriage.

\section{Trauma Symptoms}

The impact and symptoms associated with ambiguous loss often overlap with those associated with trauma. Looking at miscarriage through a trauma lens may also assist researchers and clinicians in better understanding the experience. A traumatic life event can range from violent personal attacks to natural disasters to finding out about an unexpected death (American Psychiatric Association, 2013). The process of miscarriage is unexpected and may be traumatic involving extreme pain, loss of blood, sudden hospitalization, and/or an operation (Lee \& Slade, 1996). After interviewing women who had miscarried, Wojnar, Swanson, and Adolfsson (2011) also found that the physical process of miscarriage was re-lived through painful memories similarly to how other traumas are re-experienced. Speckhard (1997) argues that when parents view the miscarriage as an unexpected death and have developed attachment to the child, then miscarriage becomes conceptualized as a trauma. Speckhard also found that symptoms following miscarriage such as loss of self and security mirror symptoms following other traumas. 
Trauma, like ambiguous loss, also has a systemic impact (Henry et al., 2011). Being in close emotional contact with someone who is traumatized may cause stress for partners and/or families. Individual PTSD symptoms are communicable, meaning those close to the individual who is traumatized may internalize the victim's experience to a point that can become harmful (Henry et al., 2011). Henry et al. found that roles, or the position each person takes in the relationship, may shift when one partner experiences trauma because the other partner takes on a more supportive and caring role than his/her previous role. Couples may also experience loss of control due to the trauma, which may lead to attempts to regain control in relationships (Henry et al., 2011). Henry et al. also found that couples may experience intimacy problems and avoidance after trauma. In sum, Henry et al. found that relationship satisfaction varies greatly among couples who have experienced trauma, which could be due to the wide range of coping mechanisms that are utilized. Nelson Goff and Smith (2005) developed a model that explains the primary and secondary trauma effects on individuals as well as interpersonal effects on the couple relationship. There are predisposing factors within each individual such as contextual elements (i.e., having experienced a previous trauma) and resources (i.e., coping) that influence the individual and couple functioning. Individual and couple functioning also mutually influence each other. Trauma affects relationships; therefore, it is crucial that researchers and professionals understand the full relational impact of a traumatic life event.

Despite the negative effects that trauma can have on an individual and/or a couple, there is also possibility for posttraumatic growth. Posttraumatic growth is defined as the positive changes made after someone experiences a traumatic event (Calhoun \& Tedeschi, 2013). Posttraumatic growth typically includes a changed sense of self, changed relationships, as well as, a changed philosophy of life. Research has found that individuals who experience and then work through their trauma may experience improved life satisfaction (Triplett, Tedeschi, Cann, 
Calhoun, \& Reeve, 2011). By viewing miscarriage as a trauma with the potential for posttraumatic growth, individuals and/or professionals may better grasp the recovery process.

\section{Current Study}

The current study aims to examine the couple experience of miscarriage by further understanding of both men's and women's reactions to miscarriage and the mutual influence each partner's individual reaction has on their partner and couple functioning. As previously cited, ambiguous loss and traumatic events can be difficult to overcome, and it is expected that couples find themselves still struggling with their loss for years following the actual miscarriage. Women may be coping with symptoms of posttraumatic stress disorder that complicate the grieving process for the individual as well as for the couple. Also, the couple may be at different points in the grieving process, which would make it difficult for the couple to make meaning of their loss together. The current study seeks to identify themes that link the experience of miscarriage to ambiguous loss and trauma so as to gain knowledge for professionals working with this population as well as knowledge for those who have experienced miscarriage. Based on Boss' (1999) theory of ambiguous loss and what we know about PTSD, the current study hypothesizes that the individual and couple experience of miscarriage will reflect similar themes associated with the impact and recovery from ambiguous loss and trauma. 


\section{CHAPTER III}

\section{METHODOLOGY}

A phenomenological perspective was used with the current study in order to gain a better understanding of the miscarriage experience. The purpose of a phenomenological study is to "describe the meaning of the lived experiences for several individuals about a concept or the phenomenon" (Creswell, 1998, p. 51). Specifically, ambiguous loss has been described as "not quantifiable, it exists phenomenologically.” (Boss, 2007, p. 107). In order to understand the phenomenon, individual experiences must be explored (Creswell, 1998). Qualitative interview data was recorded and transcribed verbatim by the researcher. Qualitative data was coded to identify salient themes associated with the couple experience of miscarriage. Quantitative survey data was used to describe individual perceptions of relationship satisfaction after experiencing miscarriage and differences in themes associated with relationship satisfaction were analyzed.

\section{Participants}

The current study recruited heterosexual couples and individual females who had experienced a miscarriage in the past six years. Seven of the 10 female participants were seeking support through support groups in Oklahoma City or Tulsa following their loss. In discussions with support group leaders, it was determined important to include all females willing to participate in order to gain a broader understanding of miscarriage and allow all females' voices to be heard. In order to be included in the current study, both the male and female partner had to 
be between 18 and 35 years of age and in a committed relationship with their partner for at least two years. Participants ranged from ages 24 to 38. All participants identified as Caucasian, and one male identified as both Caucasian and Hispanic.

\section{Recruitment}

The current study utilized convenience, snowball sampling in order to recruit couple and individual female participants. Potential participants were identified through existing relationships with support groups in the Tulsa and Oklahoma City area. In collaboration with support group leaders, potential participants were informed of the study through advertisements and brief letters distributed through social media and websites. Recruitment materials briefly introduced potential participants to the study. Couples or individual females were encouraged to call or email the researcher to express interest in participation. Prospective participants who expressed interest were contacted by the researcher who described the protocol of the study and determined whether the caller was eligible. Couples or individual females who screened eligible were informed that the study includes a number of questions about past life experiences, including previous difficult or traumatic events. Information about confidentiality, the data collection procedures, and participants' rights to refuse participation or stop the study procedures at any time was discussed. Individuals were informed that they would receive compensation for participation.

Couples or individual females meeting selection criteria and who indicated willingness and interest in participating were asked to schedule an interview at a convenient place and time that affords visual and audio privacy (i.e., participant's home, local library, OSU coding lab). Additional contact information (i.e., cell phone number, email address) was also obtained.

Data collection with each couple took 1 to 1.5 hours for couple participants and 1 hour for individual female participants. For couple participants, once participants signed the informed 
consent, one partner was asked to fill out a questionnaire in a separate room to obtain demographic data as well as measure couple satisfaction, while one partner completed a 15-20 minute audio recorded individual interview about his/her individual experiences. Examples of individual questions included: "How has your experience of miscarriage impacted you?" "How did your partner experience the miscarriage?" "Who have you talked to about the miscarriage?" Individual questions can be found in Table 1. After completing the questionnaire, a 20-30 minute semi-structured, couple interview took place. For individual female participants, following the informed consent, the participant filled out a questionnaire and then proceeded to the interview including both individual and couple questions. Follow up procedures were to debrief participants in the study and to provide referrals for grief and loss issues. The researcher provided a brief handout on mental health issues associated with miscarriage.

\section{Qualitative Measures}

Participants completed individual semi-structured, open-ended individual interviews, couple participants also completed a couple interview. Each individual interview lasted approximately 15-20 minutes and the couple interview lasted approximately 20-30 minutes. The individual and couples interview questions can be found in Table 1. 


\section{Quantitative Measures}

In addition to the demographic data, participants were asked to complete a questionnaire including the Revised Dyadic Adjustment Scale (RDAS; Spanier, 1976, as cited in Busby, Christensen, Crane, \& Larson, 1995, to assess relationship satisfaction. The RDAS is a 32-item, Likert measure assessing the quality of the relationship as perceived by both partners Total scores range from 0-151, with higher scores indicating greater relationship satisfaction. Examples of items include the following: "How often have you discussed or considered divorce, separation, or terminating your relationship?," and "Do you and your partner engage in outside interests together?" The RDAS is a frequently used, well-respected measure of relationship satisfaction. Using a sample of 486 distressed and nondistressed couples, Crane, Middleton, and Bean (2000) found Cronbach's Alpha coefficient to be .90 and Spearman-Brown split-half reliability coefficient to be .95 confirming internal consistency and reliability for the measure. Busby et al. (1995) found that there is evidence of construct validity for the RDAS, which indicates that the RDAS is an accurate measure of relationship satisfaction. The current study will use the RDAS to describe participants.

\section{Qualitative Analysis}

A phenomenological perspective was used for the current study in order to gain an understanding of miscarriage from the perspective of the couples. All interviews were audiotaped and transcribed verbatim. Interviews were analyzed using induction and deduction, a retroductive method of qualitative analysis (Nelson Goff et al., 2006). Using deduced hypotheses from previous literature and theory, the researcher analyzed the data allowing new themes to emerge while looking at those themes within the original framework. The current study hypothesized that the individual and couple experience will mirror experiences of ambiguous loss and trauma, both 
the impact and recovery process. The researcher looked at the identified themes as they associate with ambiguous loss and trauma theory.

According to the research on ambiguous loss and trauma, we would expect the following if a miscarriage were to be considered an ambiguous loss and a trauma: 1) uncertainty associated with frozen grief, 2) mixed emotions or ambivalence, and 3) symptoms of re-experiencing the event, avoidance, negative cognitions and mood, and arousal. During recovery following an ambiguous loss or trauma, we would expect the following: 1) that information regarding the loss as well processing the fact that closure is impossible, and it is necessary to find meaning in the loss, 2) skills to manage stress were necessary and helpful, 3) normalizing ambivalence, 4) that it is best to keep communication, good and bad, open, 5) social support is needed, revising attachments, and 6) spirituality and hope played an important role in recovery. The researcher identified themes from the data using Colaizzi's (1978) seven-step method: reading and rereading the participants' descriptions, extracting significant statements, formulating meanings, categorizing into clusters of themes and validating with original text, and describing (Wojnar \& Swanson, 2007). The final steps, returning to participants and incorporating any changes based on the participants' feedback, were not used by the current study. In order to compensate for excluding these steps, researchers used an external and internal auditor to enhance the trustworthiness of the themes pulled from the data. 


\section{CHAPTER IV}

\section{FINDINGS}

13 potential female participants contacted the researcher, 10 interviews were scheduled, and 10 completed data collection. All female participants viewed miscarriage as distressing thus leading to saturation of themes after 10 interviews. All 10 female participants reported having experienced at least one miscarriage, however, five reported multiple experiences of miscarriage. The most recent miscarriage for participants ranged from one month to seven years prior to the interview. All 10 female participants reported they were in a committed partner relationship. Five female participants indicated that their partner was unwilling to participate. These five female participants chose to be interviewed individually. Five female participants chose to be interviewed as a couple, reporting their partners were interested and willing to participate. All 10 female and four male participants identified as Caucasian, one male participant identified as Hispanic and Caucasian. All participants lived in either Oklahoma or Texas. In this section, I will describe the participants in order of interview prior to presenting the primary themes that emerged from the qualitative analysis of the interviews. Table 1 presents other relevant demographic information. Additionally, pseudonyms were used in order to protect participant's confidentiality

\section{Individual \#1—Whitney}

Whitney is a student with an associates degree and is in her first marriage. Whitney had two miscarriages, in 2010 and 2011. Her husband has a child from a previous relationship so she 
has one stepchild in her care. Whitney was diagnosed with major depression following her miscarriages and attempted suicide. Whitney reported coming a long way since her losses both as an individual and within her relationship.

\section{Couple \#2-Beth and Will}

Beth is an administrative assistant and Will is in business development/human resources. Both have a bachelor's degree, and Beth has a graduate degree. They are currently married, in their first marriage. They had two miscarriages in 2013, and have one adopted child. Beth and Will's most recent miscarriage was within a few months of the interview.

\section{Couple \#3-Heather and Joe}

Heather is currently clinical faculty in communication sciences, and Joe is a procurement analyst. Both have a bachelor's degree, and Heather has a graduate degree. They are currently married, in their first marriage. They had one miscarriage in 2013, and Heather is currently pregnant.

\section{Couple \#4-Kim and Ned}

Kim is a stay at home mom and part-time private music teacher, and Ned is in sales. Both Kim and Ned have a bachelor's degree. They are currently married, in their first marriage. They have had three miscarriages in 2006, 2007, and 2011, and have three biological children in their care.

\section{Individual \#5 - Gina}

Gina is a stay at home mom and is in her first marriage. Her husband is a doctor, and Gina has a bachelor's degree. She has had one miscarriage in 2009 and has one biological child in her care. She is currently pregnant. 


\section{Individual \#6-Courtney}

Courtney is a stay at home mom and is in her first marriage. She has a bachelor's degree. She had two miscarriages in 2013 and has three biological children in her care. She is currently pregnant.

\section{Individual \#7-Katie}

Katie is a retail specialist and is living with her partner. She has had some college. Katie had one miscarriage in 2008 with a partner she is no longer dating. She has one biological child in her care from a previous relationship.

\section{Individual \#8-Tayler}

Tayler is a senior administrative assistant and is currently in her first marriage. She has had some college. Tayler had one miscarriage one year ago and has one biological child in her care. 


\section{Couple \#9-Jill and Bob}

Jill is a stay at home mom and Bob is an attorney and they both have graduate degrees. They are currently married in their first marriage. Jill had one miscarriage in 2010 and they have two biological children in their care.

\section{Couple \#10_-Violet and Matt}

Violet is a stay at home mom and student and Matt is a physician. They are currently married, and this is Matt's first marriage and Violet's second marriage. They both have a graduate or professional degree. They have had four miscarriages, in 2008, 2010, 2011, and 2014, and have four biological children in their care. 
Table 1

Demographic Information for Participants

\begin{tabular}{|c|c|c|c|c|c|c|c|c|}
\hline $\begin{array}{l}\text { Female } \\
\text { participant }\end{array}$ & Age & Ethnicity & $\begin{array}{l}\text { Highest level of } \\
\text { education }\end{array}$ & $\begin{array}{l}\text { \# of } \\
\text { miscarriages }\end{array}$ & $\begin{array}{l}\text { Approximate } \\
\text { month(s) and } \\
\text { year(s) }\end{array}$ & $\begin{array}{l}\text { \# of } \\
\text { children } \\
\text { in care }\end{array}$ & RDAS & $\begin{array}{l}\text { Partner } \\
\text { RDAS }\end{array}$ \\
\hline Whitney & 24 & Caucasian & Associates degree & 2 & $\begin{array}{l}8 / 2010 \\
10 / 2011\end{array}$ & 1 & 50 & $\mathrm{~N} / \mathrm{A}$ \\
\hline Beth & 28 & Caucasian & $\begin{array}{l}\text { Graduate or } \\
\text { Professional } \\
\text { degree }\end{array}$ & 3 & $\begin{array}{l}4 / 2013 \\
11 / 2013\end{array}$ & 1 & 60 & 54 \\
\hline Heather & N/A & Caucasian & Bachelor's degree & 3 & $\begin{array}{l}\text { 12/2006, } \\
4 / 2007,8 / 2011\end{array}$ & 3 & 51 & 50 \\
\hline Kim & 36 & Caucasian & $\begin{array}{l}\text { Graduate or } \\
\text { Professional } \\
\text { degree }\end{array}$ & 1 & $3 / 2013$ & 0 & 68 & 58 \\
\hline Gina & N/A & Caucasian & Bachelor's degree & 2 & $8 / 2009$ & 1 & 49 & N/A \\
\hline Courtney & 31 & Caucasian & Bachelor's degree & 2 & $2 / 2013,9 / 2013$ & 3 & 48 & N/A \\
\hline Katie & 25 & Caucasian & $\begin{array}{l}\text { Some college, no } \\
\text { degree }\end{array}$ & 1 & $5 / 2008$ & 1 & 56 & N/A \\
\hline Tayler & N/A & Caucasian & $\begin{array}{l}\text { Some college, no } \\
\text { degree }\end{array}$ & 1 & $4 / 2012$ & 1 & 45 & $\mathrm{~N} / \mathrm{A}$ \\
\hline Jill & 32 & Caucasian & $\begin{array}{l}\text { Graduate or } \\
\text { Professional } \\
\text { degree }\end{array}$ & 1 & $5 / 2010$ & 2 & 52 & 50 \\
\hline Violet & 38 & Caucasian & $\begin{array}{l}\text { Graduate or } \\
\text { Professional } \\
\text { degree }\end{array}$ & 4 & $\begin{array}{l}8 / 2008, \\
2 / 2010, \\
9 / 2011,2 / 2014\end{array}$ & 3 & 61 & 61 \\
\hline
\end{tabular}




\section{Women's experience}

When interviewing female participants individually, I began the interview by asking each woman what she called her miscarriage experience so as to use the language she was comfortable with and would resonate with her throughout the interview. While all 10 female participants used the same terms of miscarriage or loss, each woman's description of her experience was personal in how they reported miscarriage feeling. As I asked each woman how the experience impacted her, a sense of emotional difficulty in giving the miscarriage experience language seemed to emerge as evidenced by long pauses and sighs. Several participants described their experience as heartbreaking. Heather explained, "it was the worst thing that has ever happened to me in my entire life. It was terrible. I can't even really put it into words. We just got up and went on you know everyday that you had to, but just heartbreaking." "Sad" and "hard to go through" were also common phrases used to describe the miscarriage experience. Within the women's experiences seven primary themes emerged: Emotional Toll, Stolen Dreams, No One Else Understands, Cannot Imagine Having Done It Myself, Meaning Making, and Faith.

Theme: Emotional Toll. When asking women how miscarriage impacted them, three subthemes emerged. As women told their story, it seemed as though there was this overarching emotional toll following miscarriage that began with an initial shock, continued with ongoing symptoms, and then resulted in a lasting change of a forever missing piece.

Subtheme: Initial Shock. When asked how miscarriage impacted them individually, women spoke of how the experience was shocking. The unexpected nature of the event of miscarriage seems to be the beginning of its emotional toll. Some women referred to the actual physical experience of miscarriage "traumatic." Describing her physical experience of the actual miscarriage, Tayler described her loss of blood and hospital stay as "traumatic Kim called the 
experience "shocking" emphasizing that having a miscarriage is not what a woman expects when she finds out she is pregnant.

Subtheme: Ongoing Symptoms. Several women went on to describe longer lasting psychological symptoms following miscarriage. Eight women reported symptoms of depression, such as loss of functioning, sadness, guilt, and two women reported symptoms of anxiety, such as panic attacks. Whitney said, "I couldn't function, it affected my daily life, everything. It affected how I felt, I went into a deep depression.” Gina explained, "I got very depressed, very lonely, lost a lot of friends and some family." Guilt was another common feeling reported by women following a miscarriage. When asking Heather about the hardest part, she reported, "just still thinking that I did it, I caused it." As far as anxiety symptoms, Beth described her anxiety as being exacerbated by the loss. Tayler reported, "panic attacks...I just didn't want to be alone, I didn't want to go to work, I didn't want to be asked questions... but yet I was terrified to stay home by myself."

Subtheme: The Forever Missing Piece. Two women spoke of something forever "missing" as a result of their miscarriage. It seemed as though the initial shock and symptoms subsided, but that something would be forever changed following miscarriage. I was moved by Gina's description of her experience:

You are not going to go on the same, it's not going to feel the same, you are going to feel different, there is a piece of you missing that will always be missing, but you slowly will move on.

Theme: Stolen Dreams. All 10 women mentioned expectations, hopes, and dreams when finding out they were pregnant and having those expectations, hopes, and dreams stolen by miscarriage. When asking the hardest part, half of the women reported that the stolen future for 
the child was the hardest part. I was particularly touched by Katie's description of her stolen dreams as she tearfully explained:

The hardest part I think was accepting [being pregnant] and being excited and seeing your future and knowing you are going to have something and then all of a sudden, you are not. It's not there, and it's not going to happen...having a dream and it being gone.

Theme: No One Else Understands. Nine out of the 10 women expressed the theme of isolation. Gina said in reference to the hardest part following her miscarriage was "not having people understand... if you lose a baby people are very awkward, they don't know what to say."

Seven women specifically described the experience as isolating them from their partner. Women described the experience of pregnancy and miscarriage as something physical that happened to their body, thus limiting their partner's ability to fully understand their experiences. Violet described her isolation from her partner as:

There is a difference between men and women in the process [of miscarriage]... because as soon as you find out you are pregnant as a woman, you're committed, like okay I'm pregnant there's this excitement...but my husband on the other hand has always been, even with the ones we have carried, we are in the hospital, I've delivered, and he's like oh we are going home with another kid and it hits him, but it doesn't hit him until then so it is a different process.

Katie described her partners reaction after the miscarriage, "[in reference to how miscarriage affected him] looking back that is definitely when he pulled away, he became kind of selfish." Katie and her partner ended their relationship following their miscarriage. 
Theme: He Loves Me In A Different Way. Despite nine women expressing feelings of isolation, six women spoke positively of support received from their partners. When Kim was asked how miscarriage affected her relationship with Ned, she said:

He was extremely strong and really amazing through the whole thing. You hate to say that you were closer because we were pretty close to begin, I just there's something there to know that he loves me in a different way and able to support me through all of that.

Beth reported a similar experience, feeling as though miscarriage tested their love in a different way. Beth said: "We have a very strong marriage and so it's just been something different for us to walk through together and our relationship isn't worse or better because of it, just a different aspect."

Subtheme: Cannot Imagine Having Done It Myself. Within the theme, He Loves Me In A Different Way, two women went further than being grateful for their partner's support by highlighting that they could not have recovered following miscarriage alone. Jill said, "I was very grateful that we were able to walk through that together because I cannot imagine having done it myself, that would've been impossible I think." Tayler had a similar experience and even said she "never felt closer to her husband" than she did after experiencing miscarriage together.

Theme: Why? I Don't Understand. All 10 women described wrestling with making meaning of why the miscarriage happened. Some women questioned the medical reasons for why the miscarriage happened, while others questioned the spiritual reasons. Furthermore, some women questioned why miscarriage happened to them and their family. Heather reported seeking medical answers to help cope make meaning to unanswered questions, "I wanted answers, I wanted to know...the fact that they couldn't say...that was still hard." Whitney processed how she questioned her faith and wrestled with why God would allow the miscarriage to happen, "I 
took my anger out [on God] and was like 'Why are You doing this, why would You allow this to happen'... and He didn't do it to me. God doesn't work that way.” Kim reported:

I mean I think most people when you go through something that is hard and difficult you are like why, what did we do to deserve this, why does this other family not have experienced this and everything seems to be going well so you have questions about why and I don't know that there is an answer. I think that is just how you feel, you know I think that's a feeling and I think a lot of us just coming to terms with there is not an answer.

In reference to the question how did you make sense of your loss, Courtney stated bluntly, "I honestly don't know that answer, that is something I will never understand. I don't understand the purpose of babies dying, that to me doesn't make any sense." Courtney's report was unique as she did not attempt to make sense of her losses.

Theme: In The End, I Have My Faith. After wrestling with the question of why, faith seemed to be the best answer to the struggle. Eight women reported faith being a major component of their recovery process. Gina described her faith as being her most reliable support, "The biggest thing I would say is my relationship with the Lord was huge, if I didn't have God to turn to because every person in my life failed at one point or the other but God was always there." Kim said, "my faith in God really impacted my experience going through miscarriage, I mean I don't know how I would have been able to do it without some kind of support like that." Katie also reported that her faith was important, "I've always been a Christian...everything always happens for a reason, God always has a reason for everything, giving us that baby and losing that baby, I think it made me stronger." When talking about her relationship with God following miscarriage, Courtney had a simple explanation, "It [our miscarriage] helped us refocus and rely more on God." 


\section{Men's experience}

I interviewed the men individually in the study after first interviewing their partners individually. My first question to the men was how has miscarriage impacted you as an individual, and most men answered that question by talking about their partners. As the interviews continued, the men were able to open up about their personal experience. Five themes emerged when interviewing the five men who participated in the study: Shaking My Faith, It's Not About Me, It's About Her, It's So Out Of Your Control, Relief Through Faith, Relief Through Knowing We Are Not Alone.

Theme: It's Not About Me. When interviewing the five male participants who had experienced miscarriage, it was clear that they perceived their experience as less important than their partner's experience. When asking Will about personal experience he said, "the biggest thing is just seeing her and everything she's experienced." Whitney spoke for her partner saying, "It really wasn't real to him and he doesn't, men don't experience pregnancy so they don't know what we go through. And he was just like okay you had a miscarriage but are you going to get over it..." This was similar to the other men's responses in that the miscarriage is less real for them since it happens to the female's body.

Theme: It's About Her. When asking the men to report on the hardest part, all five men reported that it was witnessing their partners experience something so difficult. Joe said:

Of course it was terrible to lose him, to lose the pregnancy, but it was equally as difficult to watch her hurt like she did, that was really difficult for me...it was tough to watch her go through that and try to be there for her and be strong...

Matt reported feeling lost as he tried to be a support for his wife: 
I know it is a lot harder on her than it is on me so I think there's just a lot more connection with a woman so for a while, she needs her space to process things and I try to be comforting but I'm not a emotional, I wish I was better at being able to talk to her about things.

When interviewing the women, I asked their perception of their partners experience and what they believed to be the hardest part for him. All five couple participants and three of the individual female participants reported that the hardest part for their partners was watching them grieve and not knowing what to do.

Theme: Shaking My Faith. When asking men about their miscarriage experience, I. Two of the men spoke of their faith and reported that they questioned God after having a miscarriage. Matt said, "I think there is a difference between guys and girls who have to go through it, it is hard and frustrating and puts a lot of tests on your faith and what God's plan is." Bob said, "When this happened it hit me like a ton of bricks, I felt at a loss, for the first time I felt like in a lot of ways I was, my faith was shaken..." Two men (Joe and Ned) reported that the experience was "shocking" and "traumatic."

Theme: It's So Out Of My Control. Another theme that emerged from interviewing the men was a loss of control. One man said, "I think every time [we miscarried] shock, because you just don't really, it's so out of your control so it's the last thing you think is going to happen." Another aspect of this loss of control was specifically in regard to not knowing what to do for their partner. Joe reported that the hardest part was “seeing her and as upset as she was...there's nothing you can really do to fix anything so that's tough to see."

Theme: Relief Through Faith, Relief Through Knowing We Are Not Alone. The final theme that emerged for men focused on recovery. Similarly to the women's experience, all five participants mentioned faith being a crucial part of their recovery process. Ned said: 
I won't ever fully understand, I know that we truly believe we will see all three of our babies in heaven and that's the biggest, relief isn't the right word, but biggest thing to take away from it is that God is in control.

Another part of the recovery process for men was awareness of how common miscarriage is. Four of the men spoke of the relief that accompanied knowing they were not the only couple who has experienced miscarriage. Bob said, "the other thing that I have learned is that we are not alone it was amazing to me to figure out how many people that we knew personally that had a miscarriage."

\section{Unique couple experiences}

After individual interviews, I brought the five couples back together to ask additional couple focused questions. I began the couple interview by asking both partners to talk to one another about how miscarriage affected their relationship. All five couples had dynamic, open communication regarding their individual interviews, which conveyed they were not hiding their experiences from one another. As engaging couples in sharing their story, a sense of relief emerged as evidenced by a more playful tone and more interaction between partners than in individual interviews with me. One couple answered my questions while holding hands. When asking in individual interviews what the hardest part was for their partner, all five couples guessed their partners' hardest part correctly, further providing evidence for the couples' open communication regarding their loss.

Theme: Strong Relationships Become Stronger. One primary theme emerged when interviewing the five couples. All five couple participants reported that they believed they had had a strong relationship before miscarrying, but that this was a "new and different experience to go through together." Bob reported that miscarriage may not have changed his relationship with 
Jill drastically but it solidified their bond, "you know I think it certainly made it stronger, definitely stronger in a sense that just being there for each other to heal during that time, I don't know if there is any residual effect from that today." Kim said:

I think it drew us closer, I think most of the time when you go through something hard and you make it to the other side you're closer, you've gone through something hard together and been able to support each other and cried together... so then when you come upon something hard again, you know you've made it through something like that before. 


\section{CHAPTER V}

\section{DISCUSSION}

The purpose of the current study was to describe the phenomenon of miscarriage from the female, male, and couple perspectives as well as to assess the potential usefulness and accuracy of using the frameworks of trauma theory and ambiguous loss theory to better understand and work with couples impacted by loss through miscarriage. Similar to other studies that have explored the experience of miscarriage (e.g., Abboud \& Liamputtong, 2003; Brier, 2008), the current study argues that this is a legitimate loss with individual and relational implications.

Research on miscarriage has tended to focus on the female perspective. Consistent with previous literature on women's miscarriage experience, the women in this study reported shock, depressive symptoms, as well as arousal symptoms (Broen et al., 2004; Schwerdtfeger \& Shreffler, 2009; Lee \& Slade, 1996). Previous studies have found that women report both guilt and emptiness (Adolfsson et al., 2004). Only one woman in the current study focused in on her guilt, which could have been a result of the timing of her loss, almost a stillbirth, or the fact that she was currently childless. 
Women in the current study did not report emptiness, which may be due to all but one woman having children in their care. Women in the current study reported that they could not imagine going through that tough experience without their partner and that their partner made them feel loved in a different way. This current finding is consistent with previous literature suggesting that partner support mediates distress for women following miscarriage (Swanson et al., 2009). A unique finding to this current study was women reporting on the importance of their faith in making sense or coming to terms with the inability to make sense of their loss.

Men in this study seemed to downplay their experience, focusing more on their female partners' experiences. Although this finding was unique to the current study, the lack of male perspective in the literature on miscarriage suggests that researchers downplay men's experience as well. The findings in this study support the literature that men feel pressure to be strong for their partners and men's reactions are greatly affected by women's reactions (Rinehart \& Kiselica, 2010; Conway \& Russell, 2000). All men in the current study reported the desire to be strong and supportive after witnessing the emotional toll miscarriage had on their partners. Similar to the previous literature (Rinehart \& Kiselica, 2010), men in the current study reported an emotional reaction of sadness, but did not report that emotional reaction lasted very long.

Men in the current study did not report coping with their emotions through externalizing behaviors as some studies have found (Johnson \& Baker, 2004; Rineheart \& Kiselica, 2010). Because the five men in the current study were willing to participate, it suggests that they may have resolved their grief and are more resilient. Another interesting finding was the relief men described by knowing that miscarriage is relatively common. Men in the current study, similarly to the women, reported that their faith was a big part of recovery, but it was the relief of knowing they were not alone that was unique. Contrary to previous research, which found that men are less likely to utilize social support (McGreal et al., 1997), the men in the current study found relief 
through a sense of community. This may not be a generalizable result as the current study only interviewed five men who reported having strong support systems.

One finding that was consistent with previous literature on the couple experience of miscarriage was that both men and women question why the miscarriage occurred. Abbound and Liamputtong (2003) interviewed couples in Melbourne and found that men and women struggle to make meaning of their loss. The current study had a similar finding, but even further, the current study found that faith is vital to make meaning of miscarriage. The importance of faith in the current study could be a due to all participants identifying as religious.

Through interviewing couples together, the researcher found that strong relationships become stronger following miscarriage. In contrast, previous studies have found that women report a distance in their relationships following miscarriage and that couples who experience miscarriage are more likely to divorce than those couples who do not experience miscarriage (Swanson et al., 2003; Shreffler et al., 2012). This discrepancy between previous literature and the current study could be due to a number of reasons. The couples who participated in the current study voluntarily contacted the researcher. Couples who are more willing to talk about their loss with those outside the relationship may have better communication skills within the relationship, thus enhancing the male partners' comfort in participating or the female participants willingness to invite their male partner to participate. These baseline communication skills may have influenced their resiliency throughout the recovery process.

For miscarriage to be conceptualized as a trauma or an ambiguous loss, we would expect two primary themes to have emerged from the interviews that describe the impact of ambiguous loss: (a) uncertainty associated with frozen grief and (b) mixed emotions or ambivalence. We would expect the following themes describing the impact of trauma: symptoms of re-experiencing the event, avoidance, negative cognitions and mood, and arousal. During recovery following an 
ambiguous loss, we would expect the following: (a) that it is necessary to find meaning in the loss and that closure is impossible, (b) that skills to manage stress were necessary and helpful, (c) that ambivalence should be normalized, (d) that it is best to keep communication, good and bad, open, (e) that social support is needed and attachments need to be revised, and (f) that hope played an important role in recovery. During recovery following trauma, we would expect the following: (a) a changed sense of self, (b) changed relationships, and (c) changed philosophy of life.

The findings in the current study suggest the impact of miscarriage may fit the framework of a traumatic ambiguous loss. The primary themes that emerged as women discussed the emotional toll described the frozen grief of ambiguous loss. Gina described her never-ending grieving process because some part of her is now forever missing. Katie reported that her grief comes in waves and will not ever be fully gone. These stories highlight the complicated grief that accompanies miscarriage. Miscarriage often lacks a clear explanation (Shreffler et al., 2011). Boss (2010) states that the unanswered questions inherent in an ambiguous loss heightens anxiety and often makes closure impossible. While it did not emerge as a saturated theme, a few participants found miscarriage to be difficult because no accepted ritual following a miscarriage exists. This finding aligns with literature on ambiguous loss (Betz \& Thorngren, 2006; Boss, 1999; Boss, 2007; Boss, 2010). Additionally, Lang et al. (2011) found that the uncertainty around a ritual as well as the general ambiguity of the loss creates stress for couples who experience miscarriage.

The second component of ambiguous loss, mixed emotions or ambivalence, was not a prominent theme found in the current study. Instead, the majority of women in this study exhibited on primary emotion of sadness. This could be because the majority of the women in the current study reported a strong desire to be mothers and sadness when this desire was not fulfilled. While mixed emotions or ambivalence were not themes that emerged from every woman's experience in the current study, one woman reported having mixed emotions regarding 
her loss. Courtney reported that she felt a "little bit of relief, guilt, and loss." Her mixed emotions may have stemmed from already having children as well as the early timing of her miscarriage.

The subtheme of Ongoing Symptoms fits trauma theory's negative cognitions and mood and arousal or anxiety symptoms. Women described those negative cognitions and mood as an overwhelming sadness, and one participant, Whitney, was diagnosed with Major Depression following her loss. Two women described their loss as exacerbating their anxiety, and one of these women reported actual panic attacks. These findings are consistent with the previous literature. Boss (2010) states that ambiguous loss has been associated with trauma symptoms, which further validates the current study's proposal that miscarriage is a traumatic ambiguous loss.

If miscarriage were to be conceptualized as a traumatic ambiguous loss, it would further legitimize the need for more research. Miscarriage has yet to be understood as a traumatic ambiguous loss, and this classification may be empowering for those affected by the loss. By raising public awareness of the experience of miscarriage, a new response from professionals and the public may be generated. Previous literature has found that couples, particularly women, feel silenced or overlooked by professionals regarding miscarriage (Brier, 2008). The current study supports this finding as many participants reported a greater need for people to speak out about their loss. Ambiguous loss and trauma already have empirical support, and by better understanding how miscarriage is a traumatic ambiguous loss, we may give women and men who experience miscarriage a stronger voice.

By conceptualizing miscarriage as a traumatic ambiguous loss, the current study suggests ways that may be particularly effective and beneficial in the recovery process. For the six components of recovery, three components were found in the current study's themes. Finding meaning seemed to be a salient theme among women and men. As highlighted by the primary 
theme, Why, I Don't Understand, women wrestled with the ambiguity of their miscarriage both spiritually and medically. Some women struggled with not knowing why they had a miscarriage whether it was "why" from a medical standpoint or "why" from a spiritual standpoint. For men in the current study, finding meaning seemed to begin with a crisis of faith. Consistent with previous literature (Boss, 2006), finding meaning in their loss seemed to be a common theme women described as they discussed their process of healing from their loss. Participants in the current study had to find a way to journey through their grief, which included a more flexible way of being. This finding aligns with the literature as Boss (2010) emphasizes ambiguous loss recovery requiring flexibility.

The necessity of social support was found in the theme He Loves Me In A Different Way. Women described needing their partners' support in the recovery process. Boss (1999) states that recovery is enhanced when family members are able to tell their stories to one another and be supportive. Spirituality and hope were found in the themes In The End, I Have My Faith and Relief Through Faith. Both women and men reported that relinquishing control to their faith was a critical point in healing following miscarriage. Boss (2010) has found that those who believe both that suffering is a natural part of life and that hope can be found are more likely to bounce back from an ambiguous loss.

Skills to manage stress and normalizing ambivalence were two components of ambiguous loss recovery not found in the themes, but one participant did report using skills learned through therapy such as validating and normalizing her emotions. Participants may not have reported specific skills because interview questions were more global than specific. Keeping communication open was not found in a theme, but it was clear through the couple interviews that individual experiences were not kept from each other. It seemed as though open communication, both good and bad, was a crucial part of strong relationships being strengthened. 
For recovery from a trauma, all three components were found in the themes. Gina, Katie, and Jill spoke on how they were forever changed after experiencing miscarriage. Gina and Katie focused more on the grief that would forever accompany them while Jill spoke on how she appreciates the miracle of life more fully. Tayler reported that she felt more human following her loss, as she realized miscarriage and the accompanying intense emotional pain is real and can happen to anyone. As reflected in the theme He Loves Me In A Different Way, women reported a changed relationship with their partner following miscarriage. Bob mentioned a change in his philosophy of life as he described shifting from a focus on occupational achievement to appreciating his family life. These findings align with previous literature on trauma recovery and posttraumatic growth (Triplett et al., 2011).

\section{Limitations and Future Research Implications}

There current study has several limitations. The first limitation is the generalizability of results. All participants identified as Caucasian, all had some college education, and all lived in either Oklahoma or Texas. The location of participants may have impacted how much faith played a role in recovery. It may be beneficial to have a larger, more diverse sample in order to increase our understanding of miscarriage. By examining miscarriage with a more diverse sample, we may also better grasp how other cultures heal following miscarriage. The participants may also be a more resilient sample. Participants contacted the researcher first which may indicate they are further along with their recovery and better equipped to speak on their experience. Additionally, conflictual couples following miscarriage may be less willing to share their experience.

Another limitation of the current study was the differences in how participants were interviewed. Some interviews were conducted as a couple and some as an individual female. When interviewing individual women, the researcher was only able to obtain their perspective of 
their partner's experience. Future studies need a clearer understanding of what is missing from the couples' relationships who were not willing to participate together. It may also be helpful for future researchers to only include both partners so as to guarantee both experiences are being reported. The current study also did not fully control for variables. Most participants had children already in their care, which may have played a part in the results. Also, the timing of the miscarriage in the pregnancy varied greatly for participants. Future studies should control for more variables such children currently in the participants care as well as the timing of miscarriage in order to better understand what makes an individual or couple resilient following miscarriage.

\section{Clinical Implications}

The current study has several clinical implications. First, having a framework for understanding miscarriage may be helpful for clinicians. Couples who experience miscarriage may feel validated by having a name for their grief as well as guidelines for living with ambiguous loss. People who experience ambiguous loss or trauma have multiple resources available to them, and if miscarriage were to be conceptualized as a traumatic ambiguous loss, it may lead to more effective healing. Herman (1992) spoke on the social movement that occurred once sexual abuse was legitimized as a trauma. Similarly to when sexual abuse was first considered a trauma, this study suggests that providing a framework for coping with miscarriage will be empowering for those who experience miscarriage. A framework for working with miscarriage may also clarify treatment goals for professionals working with those who have experienced miscarriage. Therapists may further benefit from using the six guidelines outlined by Boss (2006) for resiliency in the face of ambiguous loss.

The five couples who interviewed in the current study all reported their relationship being strengthened after supporting one another through their loss. After interviewing these couples, it may be helpful for clinicians administering couples therapy to spend time seeing partners 
individually. In the current study, it was interesting to see that all five couples accurately reported on the hardest part of miscarriage for their partner. This ability to speak accurately on a partner's experience is similar to Gottman's (2000) concept of love maps. This concept encourages couples to understand one another's experiences in order to build a stronger relationship. Another clinical implication of the current study was the importance of faith in recovery. It may be helpful for clinicians to incorporate faith as appropriate, i.e. if the couple identifies as religious, into their treatment plan when working with couples who have experienced miscarriage. 


\section{REFERENCES}

Abboud, L., \& Liamputtong, P. (2003). Pregnancy loss: What it means to women who miscarry and their partners. Social Work in Health Care, 36, 37-62. doi:10.1300/J010v36n03_03

Adolfsson, A., Larsson, P. G., Wijma, B., \& Bertero, C. (2004). Guilt and emptiness: Women's experiences of miscarriage. Health Care for Women International, 25, 543-560. doi:10.1080/07399330490444821

American Psychiatric Association. (2013). Diagnostic and statistical manual of mental health disorders: DSM-5 (5th ed.). Washington, DC: American Psychiatric Publishing.

Betz, G., \& Thorngren, J. (2006). Ambiguous loss and the family grieving process. The Family Journal, 14, 359-365. doi:10.1177/1066480706290052

Beutel, M., Willner, H., Deckard, R., \& Von Rad, M. (1996). Similarities and differences in couples' grief reactions following a miscarriage: Results from a longitudinal study. Journal of Psychosomatic Research, 40, 245-253. doi:10.1016/0022-3999(95)00520-X

Boss, P. (1999). Ambiguous loss: Learning to live with unresolved grief. Cambridge, MA: Harvard University Press. 
Boss, P. (2006). Loss, trauma, and resilience: Therapeutic work with ambiguous loss. New York, NY: W. W. Norton \& Company, Inc.

Boss, P. (2007). Ambiguous loss theory: Challenges for scholars and practitioners. Family Relations: An Interdisciplinary Journal of Applied Family Sciences, 56, 105-111. doi:10.1111/j.1741-3729.2007.00444.x

Boss, P. (2010). The trauma and complicated grief of ambiguous loss. Pastoral Psychology, 59, 137-145. doi:10.1007/s11089-009-0264-0

Brier, N. (2008). Grief following miscarriage: A comprehensive review of the literature. Journal of Women's Health, 17, 451-464. doi:10.1089/jwh.2007.0505

Brin, D. J. (2004). The use of rituals in grieving for a miscarriage or stillbirth. Women \& Therapy, 27, 123-132. doi:10.1300/J015v27n03_09

Broen, A. N., Moum, T., Bodtker, A. S., \& Ekeberg, O. (2004). Psychological impact on women of miscarriage versus induced abortion: A two-year follow-up study. Psychosomatic Medicine, 66, 265-261. doi:10.1097/01.psy.0000118028.32507.9d

Conway, K., \& Russell, G. (2000). Couples' grief and experience of support in the aftermath of miscarriage. British Journal of Medical Psychology, 73, 531-545. doi:10.1348/000711200160714

Gerber-Epstein, P., Leichtentritt, R. D., \& Benyamini, Y. (2009). The experience of miscarriage in first pregnancy: The women's voices. Death Studies, 33, 1-29. doi:10.1080/07481180802494032

Harvey, J. H., \& Miller, E. D. (Eds.). (2000). Loss and trauma: General and close relationship perspectives. Ann Arbor, MI: Taylor \& Francis. 
Henry, S. B., Smith, D. B., Archuleta, K. L., Sanders-Hahs, E., Nelson Goff, B. S., Reisbig, A. M., ... Schee, T. (2011). Trauma and couples: Mechanisms in dyadic functioning. Journal of Marriage and Family Therapy, 37, 319-332. doi:10.1111/j.1752-0606.2010.00203.x

Johnson, M. P., \& Baker, S. R. (2004). Implications of coping repertoire as predictors of men's stress, anxiety and depression following pregnancy, childbirth and miscarriage: A longitudinal study. Journal of Psychosomatic Obstetrics \& Gynecology, 25, 87-98. doi:10.1080/01674820412331282240

Klier, C. M., Geller, P. A., \& Ritsher, J. B. (2002). Affective disorders in the aftermath of miscarriage: A comprehensive review. Archives of Women's Mental Health, 5, 129-149. doi:10.1007/s00737-002-0146-2

Lang, A., Fleiszer, A. R., Duhamel, F., Sword, W., Gilbert, K. R., \& Corsini-Munt, S. (2011). Perinatal loss and parental grief: The challenge of ambiguity and disenfranchised grief. Journal of Death and Dying, 63, 183-196. doi:10.2190/OM.63.2e

Lee, C., \& Slade, P. (1996). Miscarriage as a traumatic event: A review of the literature and new implications for intervention. Journal of Psychosomatic Research, 40, 235-244. doi:10.1016/0022-3999(95)00579-X

McGreal, D., Evans, B. J., \& Burrows, G. (1997). Gender differences in coping following loss of a child through miscarriage or stillbirth: A pilot study. Stress Medicine, 13, 159-165. doi:10.1002/(SICI)1099-1700(199707)13:3<159::AID-SMI734>3.0.CO;2-5

Montgomery, J., \& Fewer, W. (1988). Family systems and beyond. New York: Human Sciences.

Nelson Goff, B. S., \& Smith, D. B. (2005). Systemic traumatic stress: The couple adaptation to traumatic stress model. Journal of Marital and Family Therapy, 31, 145-157. doi: 10.1111/j.1752-0606.2005.tb01552.x 
Nelson Goff, B. S., Reisbig, A. M. J., Bole, A., Scheer, T., Hayes, E., Archuleta, K. L.,...Smith, D. B. (2006). The effects of trauma on intimate relationships: A qualitative study with clinical couples. American Journal of Orthopsychiatry, 76, 451-460. doi: 10.1037/00029432.76 .4 .451

Rinehart, M. S., \& Kiselica, M. S. (2010). Helping men with the trauma of miscarriage. Psychotherapy: Theory, Research \& Practice, 47, 288-295. doi:10.1037/a0021160

Rowlands, I., \& Lee, C. (2010). 'The silence was deafening': Social and health service support after miscarriage. Journal of Reproductive and Infant Psychology, 28, 274-286. doi:10.1080/02646831003587346

Serrano, F., \& Lima, M. (2006). Recurrent miscarriage: Psychological and relational consequences for couples. Psychology and Psychotherapy: Theory, Research and Practice, 79, 585-594. doi:10.1348/147608306X96992

Simmons, R. K., Singh, G., Maconochie, N., Doyle, P., \& Green, J. (2006). Experience of miscarriage in the UK: Qualitative findings from the National Women's Health Study. Social Science \& Medicine, 63, 1934-1946. doi:10.1016/j.socscimed.2006.04.024

Schwerdtfeger, K. L., \& Shreffler, K. M. (2009). Trauma of pregnancy loss and infertility among mothers and involuntarily childless women in the United States. Journal of Loss and Trauma, 14, 211-227. doi:10.1080/15325020802537468

Shreffler, K. M., Greil, A. L., \& McQuillan, J. (2011). Pregnancy loss and distress among U. S. women. Family Relations, 60, 342-355. doi: 10.1111/j.1741-3729.2011.00647.x

Shreffler, K. M., Hill, P. W., \& Cacciatore, J. (2012). Exploring the increased odds of divorce following miscarriage or stillbirth. Journal of Divorce and Remarriage, 53, 91-107. doi:10.1080/10502556.2012.651963 
Speckhard, A. (1997). Traumatic death in pregnancy: The significance of meaning and attachment. In C. R. Figley, B. E. Bride, N. Mazza (Eds.). Death and trauma: The traumatology of grieving (pp. 67-100). Philadelphia, PA US: Taylor \& Francis.

Sperry, P., \& Sperry, L. (2004). The family experience of loss associated with miscarriage and ectopic pregnancy. The Family Journal, 12, 401. doi: 10.1177/1066480704267547

Swanson, K. M., Chen, H., Graham, J., Wojnar, D. M., \& Petras, A. (2009). Resolution of depression and grief during the first year after miscarriage: A randomized controlled clinical trial of couples-focused interventions. Journal of Women's Health, 18, 12451257. doi:10.1089/jwh.2008.1202

Swanson, K. M., Karmali, Z. A., Powell, S. H., \& Pulvermakher, F. (2003). Miscarriage effects on couples' interpersonal and sexual relationships during the first year after loss: Women's perceptions. Psychosomatic Medicine, 65, 902-910. doi:10.1097/01.PSY.0000079381.58810.84

Triplett, K. N., Tedeschi, R. G., Cann, A., Calhoun, L. G., \& Reeve, C. L. (2012). Posttraumatic growth, meaning in life, and life satisfaction in response to trauma. Psychological Trauma: Theory, Research, Practice, and Policy, 4, 400-410. doi:10.1037/a0024204

U.S. National Library of Medicine. (2012). Miscarriage. Retrieved from http://www.nlm.nih.gov/medlineplus/ency/article/001488.htm

Wojnar, D. M, \& Swanson, K. M. (2007). Phenomenology: An exploration. Journal of Holistic Nursing, 25, 172-180. doi:10.1177/0898010106295172

Wojnar, D. M., Swanson, K. M., \& Adolfsson, A. (2011). Confronting the inevitable: A conceptual model of miscarriage for use in clinical practice and research. Death Studies, 35, 536-558. doi:10.1080/07481187.2010.5368 


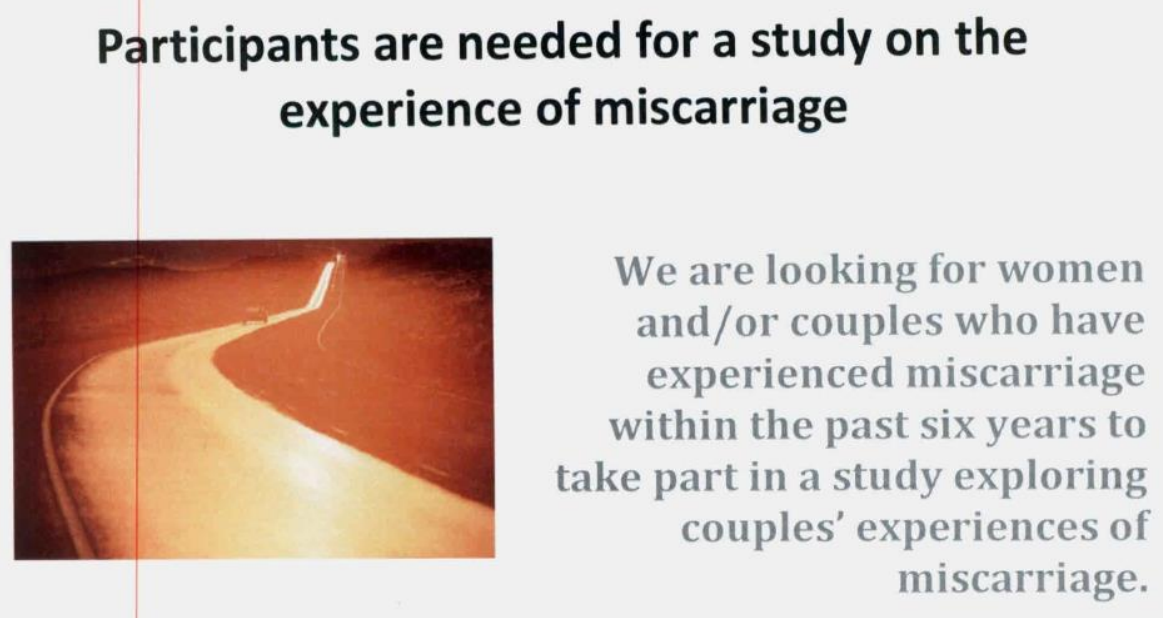

\section{What is involved?}

- You and/or you and your partner would be asked to complete a short survey and interview about your experience of miscarriage

- Participation would take 1 hour for individual females or 1.5-2 hours for couples

- In appreciation for your time, you will receive $\$ 40$ as a couple, $\$ 20$ individually

\section{Your interview would take place at}

Center for Family Services

101 Human Sciences West

Stillwater, Oklahoma 74078

(405) 744-5058

Or another mutually agreed upon convenient confidential location

\section{How do I participate?}

For more information, or to volunteer for this study, please

contact Kathleen McGee at (918.724.2991) or email at katie.mcgee@okstate.edu 


\section{Oklahoma State University Institutional Review Board}

Date: Tuesday, July 30,2013

IRB Application No HE1347

Proposal Title: Ambiguous loss: Exploring the couple's experience of miscarriage

Reviewed and Exempt

Processed as:

Status Recommended by Reviewer(s): Approved Protocol Expires: 7/29/2016 Principal Investigator(s):

Katie McGee

1212 W. 4th St.

Kami L. Schwerdtfeger

233 HES

Stillwater, OK $74074 \quad$ Stillwater, OK 74078

The IRB application referenced above has been approved. It is the judgment of the reviewers that the rights and welfare of individuals who may be asked to participate in this study will be respected, and that the research will be conducted in a manner consistent with the IRB requirements as outlined in section 45 CFR 46.

The final versions of any printed recruitment, consent and assent documents bearing the IRB approval stamp are attached to this letter. These are the versions that must be used during the study.

As Principal Investigator, it is your responsibility to do the following:

1. Conduct this study exactly as it has been approved. Any modifications to the research protocol must be submitted with the appropriate signatures for IRB approval. Protocol modifications requiring approval may include changes to the title, $\mathrm{PI}$, advisor, funding status or sponsor, subject population composition or size, recruitment, inclusion/exclusion criteria, research site, research procedures and consent/assent process or forms.

2. Submit a request for continuation if the study extends beyond the approval period of one calendar year. This continuation must receive IRB review and approval before the research can continue.

3. Report any adverse events to the IRB Chair promptly. Adverse events are those which are unanticipated and impact the subjects during the course of this research; and

4. Notify the IRB office in writing when your research project is complete.

Please note that approved protocols are subject to monitoring by the IRB and that the IRB office has the authority to inspect research records associated with this protocol at any time. If you have questions about the IRB procedures or need any assistance from the Board, please contact Dawnett Watkins 219 Cordell North (phone: 405-744-5700. dawnett.watkins@okstate.edu).

Sincerely,

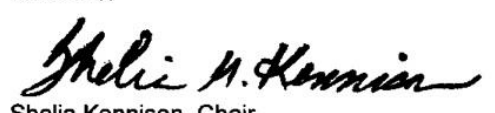

Shelia Kennison, Chair

Institutional Review Board 
DATE:

ID:

\section{Part A: BACKGROUND INFORMATION}

Age:

Gender:

1. Ethnicity: (Check all that apply)

1. $\square$ White or Caucasian

5. $\square$ Asian or Pacific Islander

2. $\square$ Black or African American

6. $\square$ Middle Eastern

3. $\square$ Spanish/Hispanic/ or Latino

7. $\square$ Other

4. $\square$ American Indian or Alaska Native $\rightarrow$ My tribe is:

2. Religious Preference: 1. $\square$ Protestant (e.g. Baptist, Lutheran, etc.) 4. $\square$ None
2. $\square$ Catholic
5. $\square$ Non-Denominational
3. $\square$ Jewish
6. $\square$ Other (Please Specify)

3. Primary Occupation:

$\rightarrow$ Are you presently: (Check all that apply) 1. $\square$ Employed full-time

2. $\square$ Employed part-time

3. $\square$ Unemployed

4. $\square$ Full-time homemaker
5. $\square$ Retired

6. $\square$ Full-time student

7. $\square$ Part-time student

8. $\square$ Other (Please

specify)

4. In what range was your total household income before taxes last year? 

1. $\square$ Under $\$ 5,000$ per year
5. $\square$ Less than $\$ 10,000$, but more than $\$ 5,000$
2. $\square$ Less than $\$ 15,000$, but more than $\$ 10,000$
6. $\square$ At least $\$ 15,000$, but less than $\$ 25,000$
3. $\square$ At least 25,000 , but less than $\$ 35,000$
7. $\square$ At least $\$ 35,000$, but less than $\$ 45,000$
4. $\square$ More than $\$ 45,000$ per year

5. Highest Level of Education Completed:
1. $\square$ Less than $9^{\text {th }}$ grade
5. $\square 9^{\text {th }}$ to $12^{\text {th }}$ grade, no diploma
2. $\square$ High school graduate (includes equivalency)
6. $\square$ Some college, no degree
3. $\square$ Associates degree (2 years)
7. $\square$ Bachelor's degree (4 years)
4. $\square$ Some graduate school
8. $\square$ Graduate or Professional Degree

6. What is your marital status?
1. $\square$ Single, never married
5. $\square$ Single, previously married
2. $\square$ Single, widowed
6. $\square$ Married, but separated
3. $\square$ Living with partner who is not the parent of your child(ren)
7. $\square$ Married, $1^{\text {st }}$ marriage
4. $\square$ Living with partner who is the parent of your child(ren)
8. $\square$ Remarried

7. How many miscarriages have you had?

Approximate month(s) and year(s)

8. Do you have children now in your care?

1. $\square$ No

2. $\square$ Yes $\rightarrow$ if yes, please specify:

Biological children $\rightarrow$ How many: 
Adopted children $\rightarrow$ How many:

Step children $\rightarrow$ How many:

Foster children $\rightarrow$ How many:

Other relative/non-relative $\rightarrow$ How many:

\section{RDAS}

Most persons have disagreements in their relationships. Please indicate below, by checking the appropriate box, the extent of agreement or disagreement between you and your partner.

\begin{tabular}{|c|c|c|c|c|c|c|}
\hline & $\begin{array}{l}\text { Always } \\
\text { Agree }\end{array}$ & $\begin{array}{c}\text { Almost } \\
\text { Always } \\
\text { Agree }\end{array}$ & $\begin{array}{l}\text { Occasionall } \\
\text { y Disagree }\end{array}$ & $\begin{array}{c}\text { Frequently } \\
\text { Disagree }\end{array}$ & $\begin{array}{l}\text { Almost } \\
\text { Always } \\
\text { Disagree }\end{array}$ & $\begin{array}{l}\text { Always } \\
\text { Disagree }\end{array}$ \\
\hline $\begin{array}{l}\text { 1) Religious } \\
\text { matters }\end{array}$ & & & & & & \\
\hline $\begin{array}{l}\text { 2) Demonstrations } \\
\text { of affection }\end{array}$ & & & & & & \\
\hline $\begin{array}{l}\text { 3) Making major } \\
\text { decisions }\end{array}$ & & & & & & \\
\hline 4) Sex relations & & & & & & \\
\hline $\begin{array}{l}\text { 5) Conventionality } \\
\text { (correct or proper } \\
\text { behavior) }\end{array}$ & & & & & & \\
\hline 6) Career decisions & & & & & & \\
\hline
\end{tabular}

\begin{tabular}{|c|c|c|c|c|c|c|}
\hline & All the time & $\begin{array}{l}\text { Most of the } \\
\text { time }\end{array}$ & $\begin{array}{l}\text { More often } \\
\text { than not }\end{array}$ & $\begin{array}{l}\text { Occasion- } \\
\text { ally }\end{array}$ & Rarely & Never \\
\hline $\begin{array}{l}\text { 7) How often do you discuss or } \\
\text { have you considered divorce, } \\
\text { separation, or terminating you } \\
\text { relationship? }\end{array}$ & & & & & & \\
\hline $\begin{array}{l}\text { 8) How often do you and your } \\
\text { partner quarrel (or argue)? }\end{array}$ & & & & & & \\
\hline $\begin{array}{l}\text { 9) Do you ever regret that you } \\
\text { married (or lived together)? }\end{array}$ & & & & & & \\
\hline $\begin{array}{l}\text { 10) How often do you and your } \\
\text { partner "get on each other's }\end{array}$ & & & & & & \\
\hline
\end{tabular}




\begin{tabular}{|l|l|l|l|l|l|l|}
\hline nerves"? & & & & & & \\
\end{tabular}

\begin{tabular}{|l|l|l|l|l|l|}
\cline { 2 - 5 } \multicolumn{1}{c|}{} & Every day & $\begin{array}{c}\text { Almost } \\
\text { every day }\end{array}$ & Occasionally & Rarely & Never \\
\hline $\begin{array}{c}\text { 11)Do you and your partner engage in } \\
\text { outside interests together? }\end{array}$ & & & & & \\
\hline
\end{tabular}

How often would you say the following events occur between you and your partner?

\begin{tabular}{|c|c|c|c|c|c|c|}
\hline & Never & $\begin{array}{c}\text { Less than } \\
\text { once a } \\
\text { month }\end{array}$ & $\begin{array}{c}\text { Once or } \\
\text { twice a } \\
\text { month }\end{array}$ & $\begin{array}{c}\text { Once or } \\
\text { twice a } \\
\text { week }\end{array}$ & Once a day & More often \\
\hline $\begin{array}{l}\text { 12) Have a stimulating exchange of } \\
\text { ideas }\end{array}$ & & & & & & \\
\hline 13) Work together on a project & & & & & & \\
\hline 14) Calmly discuss something & & & & & & \\
\hline
\end{tabular}


VITA

\author{
Kathleen Rebecca McGee \\ Candidate for the Degree of
}

Master of Science

\title{
Thesis: AMBIGUOUS LOSS: A PHENOMENOLOGICAL EXPLORATION OF WOMEN SEEKING SUPPORT FOLLOWING MISCARRIAGE
}

Major Field: Human Development and Family Science

Biographical:

Education:

Completed the requirements for the Master of Science/Arts in your major at Oklahoma State University, Stillwater, Oklahoma in May, 2014.

Completed the requirements for the Bachelor of Science in Human Development and Family Science at Oklahoma State University, Stillwater, Oklahoma in 2011.

Experience:

Therapy Intern

Center for Family Services, Stillwater, Oklahoma, March 2012-December 2013

Therapy Intern

Payne County Youth Services, Stillwater, Oklahoma, July 2012-July 2013

Research Assistant

Department of Human Development and Family Science, Oklahoma State University, August 2011-April 2014

Professional Memberships:

American Association of Marriage and Family Therapy

Oklahoma Association of Marriage and Family Therapy 